\title{
A Method for Traffic Calming Using Radio Transmitter
}

\author{
Amin Mirza Boroujerdian and Samane Sheikhy \\ Civil \& Environment Engineering Faculty, Tarbiat Modares University, Tehran, Iran \\ Correspondence should be addressed to Amin Mirza Boroujerdian; boroujerdian@modares.ac.ir \\ Received 2 August 2016; Revised 13 October 2016; Accepted 6 November 2016; Published 12 January 2017 \\ Academic Editor: Sze Chun Wong
}

Copyright (c) 2017 A. M. Boroujerdian and S. Sheikhy. This is an open access article distributed under the Creative Commons Attribution License, which permits unrestricted use, distribution, and reproduction in any medium, provided the original work is properly cited.

\begin{abstract}
Excessive speed is one of the major factors in transportation safety assessment and is influenced by road geometric design, vehicle properties, and driving pattern. Exploiting innovative methods along with the conventional ones has been proven to be effective in road safety to control the speed limit. In this study, a supplementary tool is introduced to help drivers to observe the speed limit. In line with this objective, the effectiveness of Voice Sign System (VSS) as an Intelligent Transportation System is evaluated. In order to measure the speed, video processing software is used. Moreover, SPSS is utilized to perform statistical analysis and compare upstream and downstream speeds before and after a message transmission. The study is conducted in Yadegar-e-Imam expressway, located in Tehran, to evaluate the effectiveness of a voice message. The message reads as follows: "Observe the Speed Limit." The results reveal that VSS is an effective tool for speed reduction as well as the speed limit observation in expressways. The study shows that the speed is reduced by $18 \%$ on average, and speed limit observation is improved by $46.5 \%$, out of which $18.2 \%$ is direct and $28.3 \%$ is indirect influence of VSS.
\end{abstract}

\section{Introduction}

The inconsistency between functional speed, traffic capacity, and road safety results in roads accidents. Functional speed or 85th percentile speed is the speed at which 85 percent of drivers drive at that speed or slower than that. Different kinds of traffic calming measures can be used to the above mentioned problem. Road traffic injuries are the 8th leading cause of death throughout the world and the second in Iran [1]. Moreover, according to Iranian Legal Medicine Organization, the number of road accident casualties in a period of 6 years (i.e., 2006 to 2012) was estimated to be 23,373 on average [2]. The considerable number of road accident casualties in Iran is a serious concern. Therefore, different innovative actions ought to be taken into account to address the problem.

Up until 2012, Tehran expressways were equipped with 90 speed cameras. The cameras record approximately 10 to 12 thousands traffic offence regarding exceeding the speed limit everyday [3]. The recorded numbers clearly show that many drivers in Tehran violate the traffic rules.

Exceeding the speed limit in developed countries such as the US, Australia, and New Zealand is accountable for $30 \%$ to $35 \%$ of road injuries. In Iran it is an important factor in fatal accident occurrence as well. During 1995 to 2003 the number of the accidents in Iran increased dramatically. That is to say, on average 317,346 accidents occurred annually, out of which 78,016 cases resulted from exceeding the speed limit (24.5\% of the total number of accidents in that period) [4].

Different traffic signs are used to control the traffic and increase the road safety. In addition to pavement marking and temporary signs, there are three main signs, namely, disciplinary, warning, and declarative. Speed limit signs which are categorized into disciplinary signs are applied to display the minimum and maximum speeds in highways. Additionally, messages related to the speed limit observation are displayed using variable message signs. Since $90 \%$ of the information received by the drivers is visual, applying a complementary method such as audio messages can be beneficial and result in diminution of drivers' error in receiving the messages. Moreover, the probability of perceiving the information increases [5].

The present research intends to evaluate the effectiveness of the voice message "Observe the Speed Limit" on the operational speed reduction. Additionally, the effect of the message on changing the driver's behavior and the percentage of drivers who reduce their speed are analyzed and reported. 


\section{Literature Review}

Speed Reduction is an important parameter in road safety improvement which can be applied using traffic calming measures, traffic control devices, and Intelligent Transportation Systems (ITS). These solutions can be used in different situations to improve drivers' safety. As for traffic calming measures, there are various types of equipment used for observing the speed limit. These tools include vertical speed control measures such as speed humps, raised intersections and speed tables, horizontal equipment like roundabouts and lateral shifts, and finally narrowing the roads such as necking down and island narrowing [6].

Furthermore, traffic control equipment consists of vertical signs such as traffic signs, traffic lights, and horizontal signs like markings, notices, marked signs, and so forth [7]. As mentioned earlier Intelligent Transportation Systems are generally classified into three different sections of surveillance (Closed Circuited Television Cameras (CCTV)), Control (speed camera devices), and driver's information (variable message signs) [8].

Applying speed humps as a traffic calming tool is common where there are vulnerable road users like residential areas and schools. Antić et al. studied the influence of speed humps' heights on the vehicle's speed reduction. The results showed that the speed humps with different heights of 3,5 , and 7 centimeters yielded to $13 \%, 30 \%$, and $35 \%$ reduction in 50th speed percentiles, respectively [9]. The results also revealed that despite the fact that speed humps were efficient in reducing the speed, the number of rear-end collisions increased since drivers applied the brakes unexpectedly to avoid an accident. Another study was conducted to evaluate 150 different speed management schemes in Britain. The results showed that the speed humps were the most effective traffic calming method. In other words, they reduced the number of fatal accidents and speed by $44 \%$ and $38 \%$, respectively [10].

Using pavement marking and signs can also be effective in controlling and reducing the speed. Ding et al. used driving simulation to evaluate the effectiveness of speed reduction using speed reduction markings (SRMs). Statistics showed that, out of 15 drivers, the percentage of speed reduction was 7\% in no SRMs, $13 \%$ in longitudinal SRMs, and $47 \%$ in transverse SRMs scenarios [11]. Moreover, study on chevron pavement marking in America expressed that it was accountable for reduction in 85th percentile speed to about $25 \mathrm{Km} / \mathrm{h}$. Also, 43\% reduction in crashes occurred on ramps was observed [12]. Contrary to speed humps, SRMs did not damage the vehicles, and their effect was long lasting as they extended on a larger part of a road.

Visibility of speed cameras is also important in controlling and reducing the speed. The visibility resulted in 30\% decrease in collisions in arterial streets located in Melbourne, Australia [13]. The results of a study conducted for the first time in the US revealed that mounting speed cameras was an efficient tool in speed reduction. Moreover, it was concluded that exceeding the speed limit $(65 \mathrm{~km} / \mathrm{h})$ to more than $17.7 \mathrm{~km} / \mathrm{h}$ decreased by 88 percent [14].
In China, a study was carried out to assess the effectiveness of Automated Speed Enforcement (ASE) on reducing the speed of vehicles. The effective zone of speed cameras in cantilever was about 1.6 to $2 \mathrm{~km}$ and it was $1 \mathrm{~km}$ for speed cameras on the roadside. On expressways where cameras were mounted on the cantilever and roadside and the speed limit was $100 \mathrm{~km} / \mathrm{h}$, the speed reduction was $50 \%$ and $29.3 \%$, respectively. And on the expressways with roadside cameras where the speed limit was $120 \mathrm{~km} / \mathrm{h}$, the speed reduction was $17.4 \%$ [15].

In Iran, speed cameras are used to record speed limit violation, spot velocity, and traffic volume. In 2009, implementation of speed cameras on Niyayesh and SayadeShirazi expressways located in Tehran led to $60 \%$ reduction in speed limit violation. They are also accountable for reducing $100 \%$ of accidents resulting in death as well as $40 \%$ reduction in crashes. Up until 2013, 16 expressways in Tehran have been equipped with 120 speed cameras. The benefits were $60 \%$ reduction in road injuries as well as decreasing the number of fatal accidents to zero [3]. The results showed that mounting smart speed cameras were more effective than speed humps and pavement markings in speed reduction. Therefore, applying smart and innovative traffic calming equipment is very effective.

In previous studies, different methods including installing traffic signs and intelligent and nonintelligent equipment were applied to control and reduce the speed of vehicles. Providing each measure is timely applied, drivers will have enough time to react and respond accordingly. Therefore, measures requiring shorter reaction time are more preferable. Reaction time for different signs depends on the type of perceived messages by drivers. Drivers usually respond to audio signs faster than visual signs. The response time to audio and visual signs is 150 and 200 milliseconds, respectively. Additionally, drivers response to the combination of audio-visual signs faster than each sign alone [16]. Furthermore, measures used to reduce vehicles' speed should encompass the need of elderly drivers and young ones. Elderly drivers need a longer reaction time due to their poor eyesight and young drivers tend to ignore traffic signs and might not be as focused as they must be, while driving. Consequently, measures need to be efficient and comprehensive enough to all ranges of drivers.

Currently, there are some systems which send information on traffic density, crashes, and critical situations ahead of drivers using communication devices. Radio Data System (RDS) is only capable of receiving the information only if the vehicle radio device is equipped with RDS. In critical situations, information is sent to an extensive area by the main telecommunication centers using warning alarms and text messages. The system was developed as a European standard by European Broadcast Union (EBU) in 1998 and the first improvements were developed in Germany [17]. Vehicle Information and Communication System (VICS) for vehicles is available in Japan since 1996, which enables drivers to receive traffic information as a text or on a map in their vehicles [18].

The Connected Vehicle Technology (CVT) sends location information of car accidents to the other vehicles using 


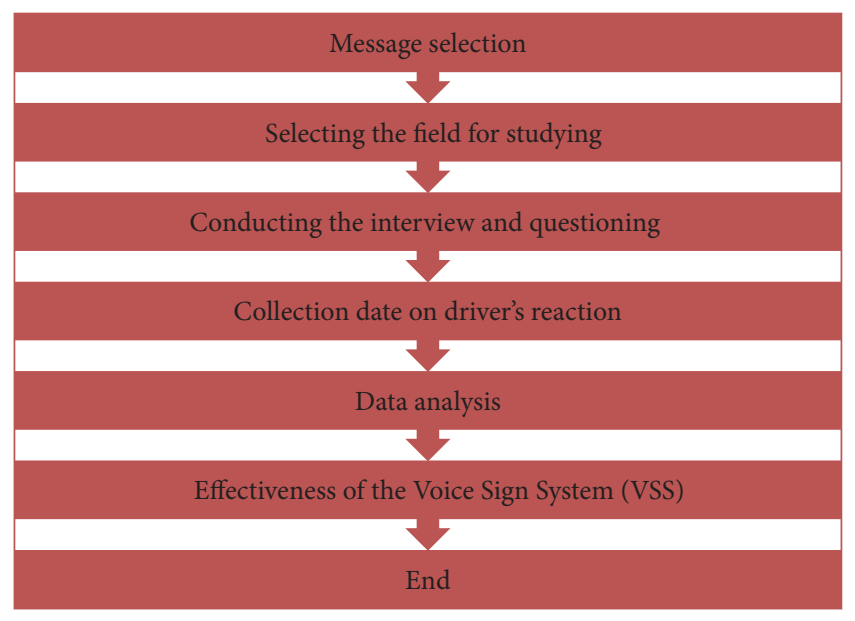

FIGURE 1: Research procedure.

vehicle to vehicle communication technology. Each vehicle resends its geographical information to the other vehicles. The director of National Highway Traffic Safety Administration (NHTSA) claimed that vehicle communication technology can reduce road accidents by 80 percent [19].

In this research, the effectiveness of VSS on reducing the vehicle speed was evaluated. This system is capable of transmitting various voice messages to the radio of vehicles and requires no supplementary equipment. Moreover, in contrary to RDS and VICS systems, VSS transmits voice messages locally. Provided that the VSS is connected to the speedometer sensors in the upstream area it is possible to transmit the messages when necessary.

\section{Procedure of Experiment}

Figure 1 illustrates the flowchart used in research.

In order to transmit the voice message, a transmitter was developed being able to transmit the audio input to radio receivers. According to a survey conducted by Research Center of Islamic Republic of Iran Broadcasting, radio channels of Iran, Javan, Payam, and Varzesh are the most popular radio stations [20-22]. If the vehicle radio is on and tuned in one of those frequencies, as the driver travels through the zone where the transmitter is active, the audio message will be heard. Owing to the transmitter capability, even drivers driving faster than $120 \mathrm{~km} / \mathrm{h}$ can hear the message at least once. Thanks to transmitter USB flash drive, the messages can be conveniently modified. The transmitter also is capable of transmitting several messages continuously and repeatedly. The device shown in Figure 2 is small and portable and the batteries are rechargeable. The transmitter can transmit various traffic, warning and declarative messages, and virtually all audio messages. However, in the present study, only the message "Observe the Speed Limit" was selected and evaluated as its highest priority among other messages.

A four-lane part of Yadegar-e-Imam expressway which is the main north-south arterial in north-west of Tehran was selected as field study to collect data, and drivers' behaviors

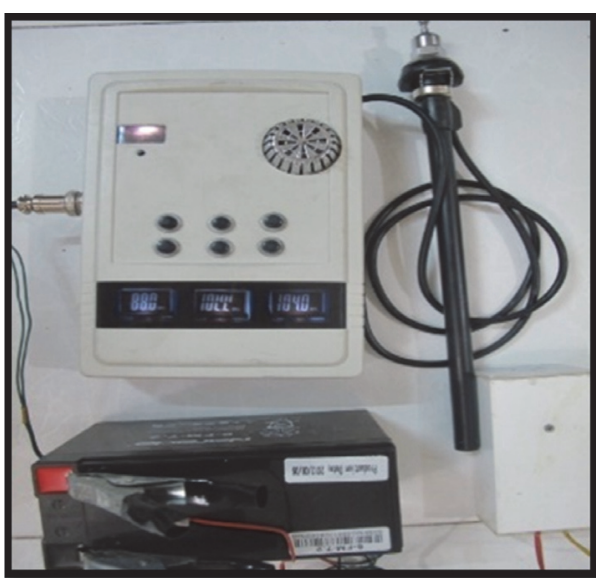

Figure 2: The radio transmitter and accessories.

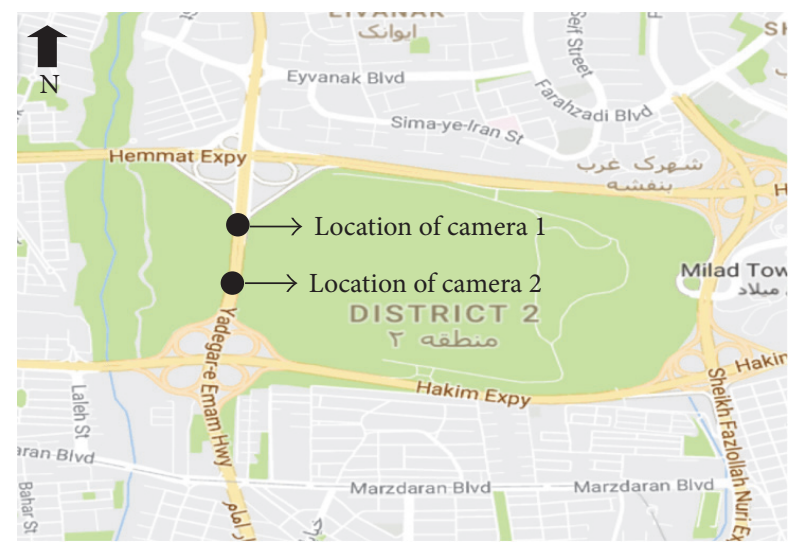

FIGURE 3: The location of speed camera.

who were driving north to south were studied. The arterial of north-south was selected for its high slope and drivers' tendency to exceed the speed limit. Also, speed cameras of Tehran Traffic Control Center have recorded many exceeding speed limitation violation in the arterial since the implementation of speed cameras. Figure 3 illustrates the location of the study area and speed cameras.

Data were collected in the stable weather conditions. The speed limit was $80 \mathrm{~km} / \mathrm{h}$ and two speed cameras were mounted. In order to evaluate the effect of the traffic signs and speed cameras, data regarding speed of vehicles were collected in both upstream and downstream of the zone without the voice transmission. Data gathered by speed cameras showed that traffic violations and traffic volume reached the peak values at 2 to 3 p.m. [3]. Since, in that period, vehicles travelled fast, it was not considered as peak hour. Therefore, that period was selected for data collection. Sunday and Tuesday (weekdays in Iran) were chosen for data collection as the vehicles' speed and traffic volume were not affected by the weekend traffic volume and traffic violations.

Two speed cameras with the distance of 350 meters from each other were used and are shown in Figure 4. The first camera collected the data before hearing the message, and the second one recorded the data after the message was 


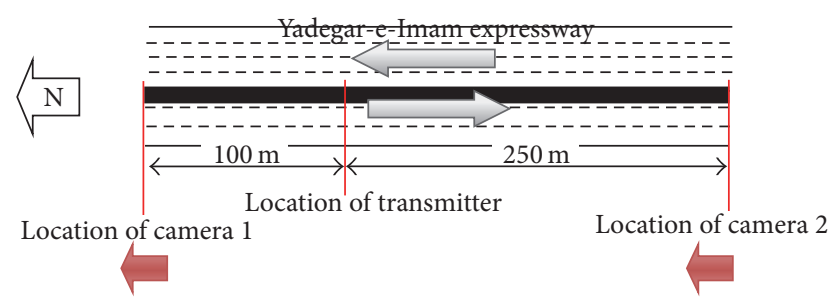

FIGURE 4: Location of cameras and the transmitter.

transmitted and heard. The VSS was installed 100 and 250 meters away from the first and second camera, respectively. The distance between the voice message and the second camera was determined to be 250 meters so that the drivers had enough time to comprehend and respond to the message.

Two cameras were installed on two bridges over the expressway to observe the area under study. Figure 5 shows the areas covered by both cameras. By means of cameras and the transmitter, the audio message was transmitted in accordance with the features and disciplinary signs in the area. The message of "The speed limit is $80 \mathrm{~km} / \mathrm{h}$ " was repeatedly played and transmitted.

The device transmitted the voice message simultaneously to only four specific radio frequencies (Iran, Javan, Payam, and Varzesh). A survey was conducted on 176 randomly selected drivers to evaluate the direct and indirect effect of the Voice Sign System on drivers' behavior and reaction. The first group, who were directly influenced by the message, heard the message and in response reduced their speed. The second group, who were indirectly influenced by the message, reduced their speed as well. Although the second group of drivers probably did not hear the voice, the speed reduction by the first group affected their driving behavior. The survey was conducted on Sunday and Tuesday between 2 and 3 p.m. to determine the percentage of the drivers who were listening to the radio on the four aforementioned frequencies. An interview was held in Hormozan-Jey intersection at the terminal of Yadegar-e-Imam expressway. Based on the main objective of the study, questions were as follows:

(1) Were you listening to the radio?

(2) If yes, which radio frequencies were used?

Video processing software was used to analyze the data and changes in speed of vehicles due to the audio message. The software determined the speed of vehicles using the recorded movies. Videos recorded by first and second cameras were simultaneously played and each vehicle was tagged before and after sending the message so as to determine the speed of each vehicle before and after hearing the message. Figure 6 demonstrates simultaneous selection of the vehicles in video analysis in order to measure the vehicle speed.

To analyze the data collected regarding the vehicle speed, relative and cumulative frequencies distribution curves were measured for two statuses, namely, transmission of the voice message and transmission of no voice message. Then, the difference in vehicles' speed, before and after the message transmission, was studied. The statistical tests of KolmogorovSmironov and Shapiro-Wilk were conducted to examine the
TABle 1: Passing vehicles speed data.

\begin{tabular}{lc}
\hline $\begin{array}{l}\text { Date of data collection in the } \\
\text { status of sending the voice } \\
\text { message }\end{array}$ & $\begin{array}{c}\text { Sunday September 22, 2013, and } \\
\text { Tuesday September 24, 2013 }\end{array}$ \\
\hline $\begin{array}{l}\text { Date of data collection with no } \\
\text { message transmission }\end{array}$ & Sunday September 17, 2013 \\
$\begin{array}{l}\text { Duration of the speed data } 15 \\
\text { collection }\end{array}$ & 508 vehicles \\
$\begin{array}{l}\text { The number of speed data in the } \\
\text { status of sending the voice } \\
\text { message }\end{array}$ & 158 vehicles \\
$\begin{array}{l}\text { The number of speed data with } \\
\text { no message transmission }\end{array}$ & $\begin{array}{l}\text { Average volume of the through } \\
\text { traffic at the time of sending the } \\
\text { voice message }\end{array}$ \\
$\begin{array}{l}\text { Average volume of the through } \\
\text { traffic with no message } \\
\text { transmission }\end{array}$ & 1758 vehicles in each lane every \\
\end{tabular}

normality of the data frequency. Also, a $t$-test was applied to measure the significance of mean speed in the upstream and downstream of the area, with message transmission and no transmitted message, to consider the effect of two mentioned statuses. Finally, the effectiveness of the Voice Sign System on observing the speed limit was evaluated.

\section{Results}

The present study was based on analysis of the relevant speed data and the conducted interview. Table 1 shows the collected data properties obtained from speed of vehicles. It follows by data collected from the interviews, analyzing curves of vehicle speed frequencies, comparing average speed and 85th percentile speed in two situations, and determining the effect of the message on speed limit observation. Finally, the effect of the message on the drivers' speed was also evaluated using statistical tests.

4.1. The Survey Results. The result of the survey revealed that $79 \%$ of the drivers were not listening to the radio and only $21 \%$ of them listened to the radio out of which $18.2 \%$ listened to one of the four frequencies in which the voice message was transmitted through Iran, Javan, Payam, and Varzash.

\subsection{Analyzing Speed Frequencies of the Passing Vehicles.} Figures 7 and 8 illustrate relative and cumulative frequency curves for the status of transmitting a message and no transmitted messages, respectively.

In order to determine the disturbing factors on speed changes, speed data were collected in the upstream and downstream of the study area. According to Figure 7, the cumulative frequency distribution curves are almost identical demonstrating that there are no factors in the upstream and downstream of the area under study.

Based on Figure 8, the speed cumulative curve related to message transmission downstream area is on the left and 


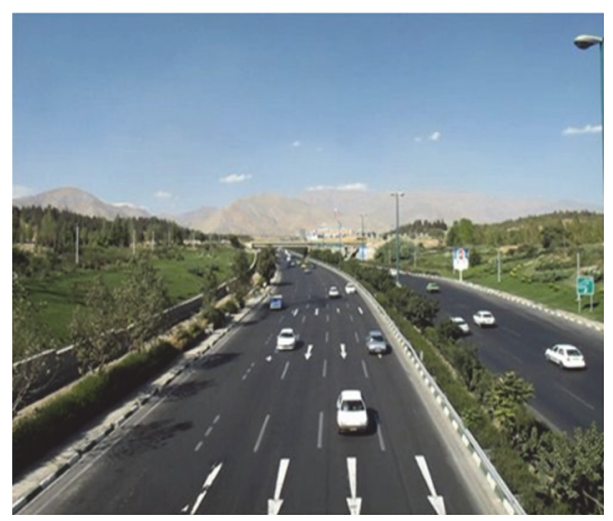

(a)

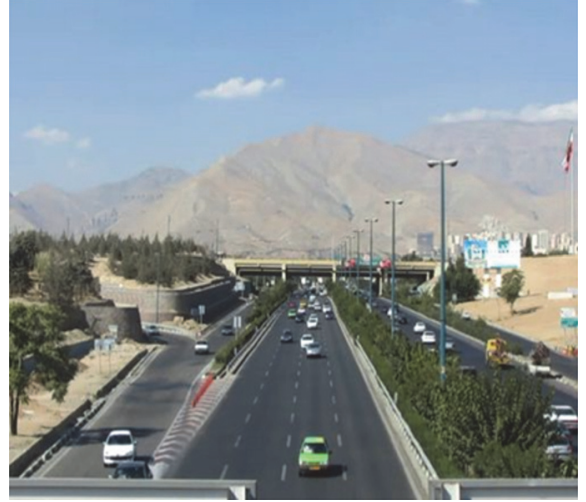

(b)

Figure 5: The areas covered by the first camera (upstream) and the second camera (downstream) are shown (b) and (a), respectively.

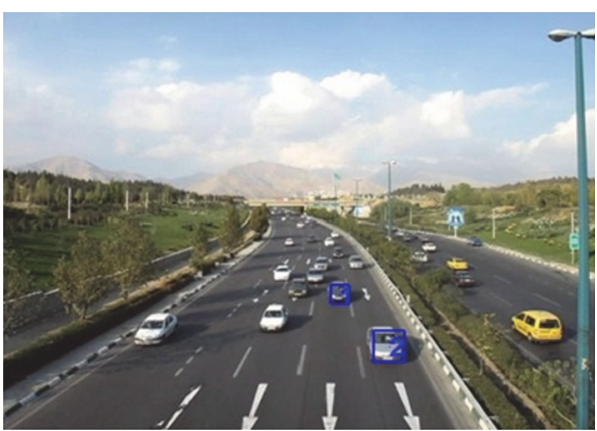

(a)

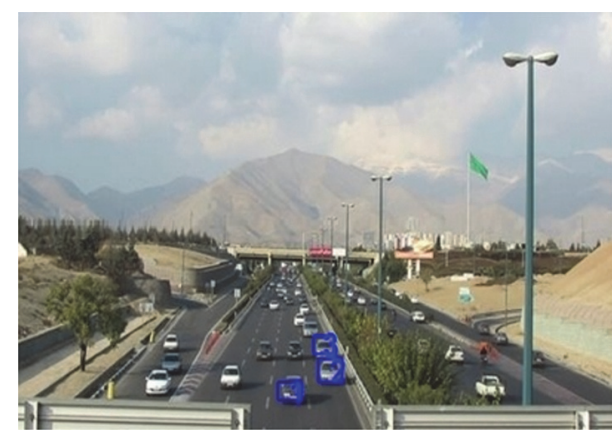

(b)

Figure 6: A sample from simultaneous selection of the vehicles in video analysis in order to measure the vehicle speed ((b) first camera (upstream) and (a) second camera (downstream)).

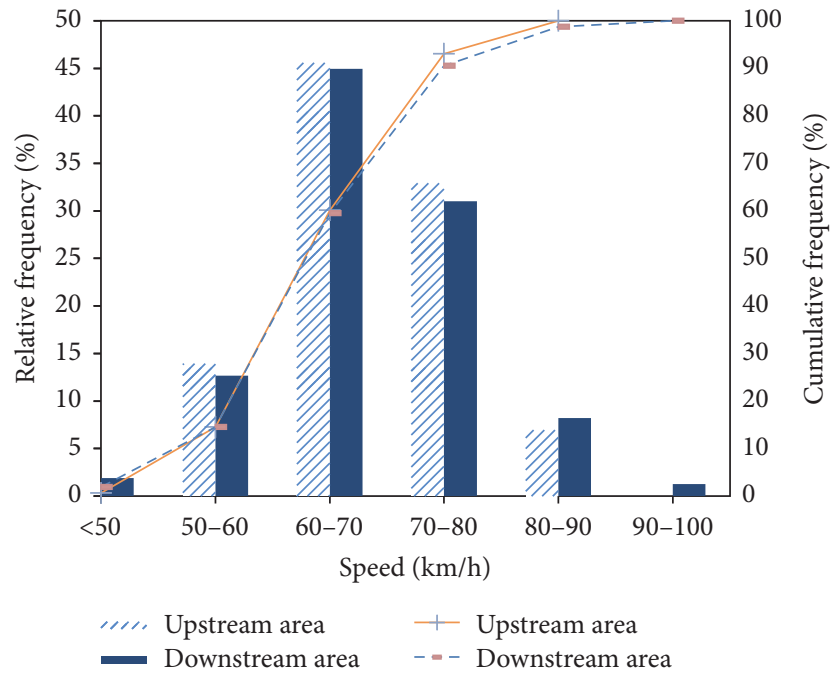

FigURE 7: Relative and cumulative frequency distribution of speed in the status of not transmitting any messages.

the speed cumulative curve before the message transmission in upstream is on the right showing the significance of speed changes before and after the message transmission, respectively. Therefore, it seems that the speed is reduced. Additionally, it is concluded that $24.6 \%$ of vehicles are travelling $80 \mathrm{~km} / \mathrm{h}$ and slower before the message transmission (upstream) which is reduced to $67.9 \%$ after the message transmission (downstream).

4.3. Statistics Analysis. Table 2 compares mean 50th percentile and 85th percentile speed of the status using VSS. According to the condition with no message transmission, the upstream and downstream mean and 85th percentile speed are identical, and the difference is insignificant. Thus, it is concluded that geometric terrain (slope), traffic complications (merge or diverge), speed cameras, and traffic signs will have no considerable effect on the speed and vehicles pass at a steady speed. Therefore, any speed change that occurred resulted from the message transmission (refer to Figure 9). According to the result of Table 2, the message resulted in $18 \%$ reduction in the mean speed (the mean speed reduced to $16.6 \mathrm{~km} / \mathrm{h}, \mathrm{SD}=15.8$, and $\mathrm{SE}=0.701), 19 \%$ reduction in the 50th percentile speed (reduction of 50th percentile speed to $18 \mathrm{~km} / \mathrm{h} ; \mathrm{SD}=15.8)$, and $22 \%$ reduction in the 85 th percentile speed (reduction of 85 th percentile speed to $24 \mathrm{~km} / \mathrm{h}$; SD = 15.8). As shown in Figure 10, the above mentioned results reveal VSS effectiveness in vehicles' speed reduction. 
TABLE 2: The speed data summary in different scenarios.

\begin{tabular}{|c|c|c|c|c|c|c|c|c|}
\hline Location & $V_{\min }$ & $V_{\max }$ & $V_{\text {mean }}$ & $V_{50}$ & $V_{85}$ & $\Delta V_{\text {mean }}$ & $\Delta V_{50}$ & $\Delta V_{85}$ \\
\hline Upstream area (the message is transmitted) & 47 & 139 & 92 & 93 & 110 & \multirow{2}{*}{-16.6} & \multirow{2}{*}{-18} & \multirow{2}{*}{-24} \\
\hline Downstream area (the message is transmitted) & 42 & 113 & 75.4 & 75 & 86 & & & \\
\hline Upstream area (no message is transmitted) & 50 & 88 & 68.5 & 68 & 76 & \multirow{2}{*}{0.29} & \multirow{2}{*}{0} & \multirow{2}{*}{2} \\
\hline Downstream area (no message is transmitted) & 45 & 100 & 68.8 & 68 & 78 & & & \\
\hline
\end{tabular}

$V_{\min }=$ minimum speed, $V_{\max }=$ maximum speed, $V_{\text {mean }}=$ mean speed, $V_{50}=50$ th percentile speed, $V_{85}=85$ th percentile speed, $\Delta V_{\text {mean }}=$ difference of mean speed, $\Delta V_{50}=$ difference of 50th percentile speed, and $\Delta V_{85}=$ difference of 85 th percentile speed.

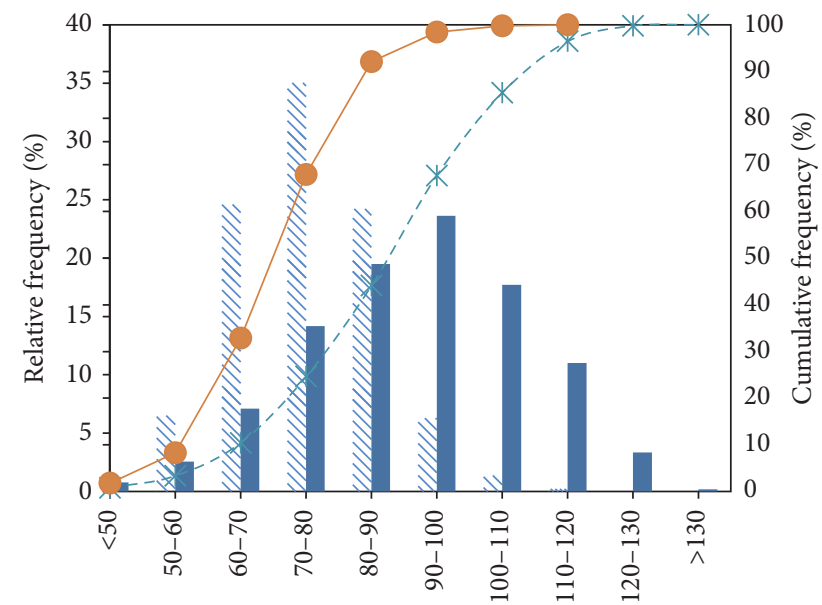

Speed $(\mathrm{km} / \mathrm{h})$

… After sending message (downstream area)

- Before sending message (upstream area)

-* Before sending message (upstream area)

-- After sending message (downstream area)

FIGURE 8: Relative and cumulative frequency distribution of speed in the status of sending a message.

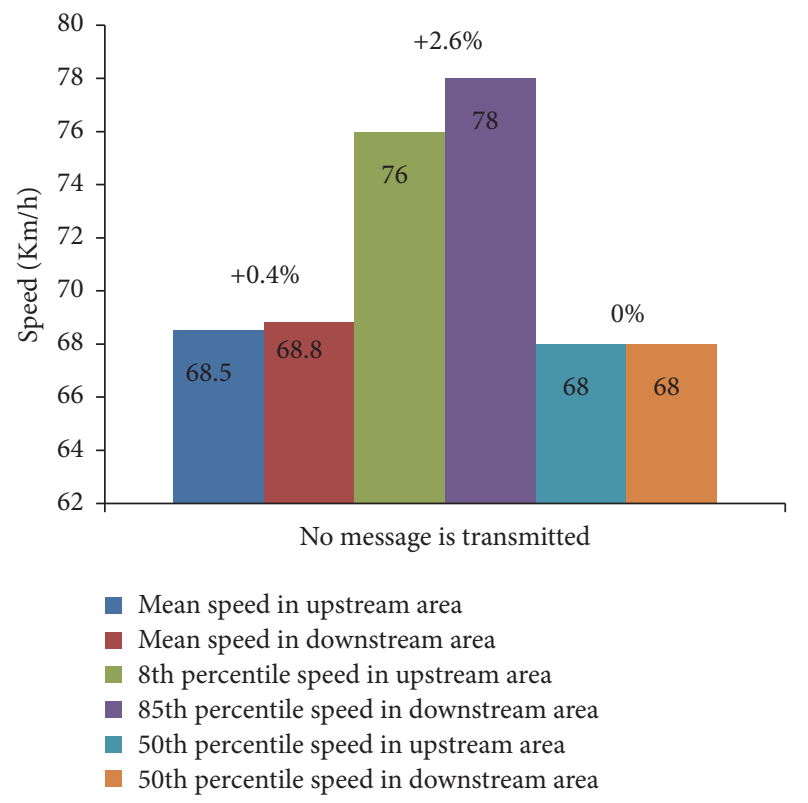

FIgURE 9: Changes in mean and 50th percentile and 85th percentile speed when no messages are transmitted.
TABLE 3: Speed changes when massage is transmitted.

\begin{tabular}{lcccc}
\hline Subject & $\begin{array}{c}\text { Mean speed } \\
\text { before } \\
\text { sending the } \\
\text { message } \\
(\mathrm{km} / \mathrm{h})\end{array}$ & $\begin{array}{c}\text { Mean speed } \\
\text { after } \\
\text { sending the } \\
\text { message } \\
(\mathrm{km} / \mathrm{h})\end{array}$ & $\begin{array}{c}\text { Changes } \\
\text { in mean } \\
\text { speed } \\
(\mathrm{km} / \mathrm{h})\end{array}$ & $\begin{array}{c}\text { Percentage } \\
\text { of speed } \\
\text { changes }\end{array}$ \\
\hline $\begin{array}{l}\text { Status of } \\
\text { sending the } \\
\text { message }\end{array}$ & 92 & 75.4 & -16.6 & $-18 \%$ \\
\hline
\end{tabular}

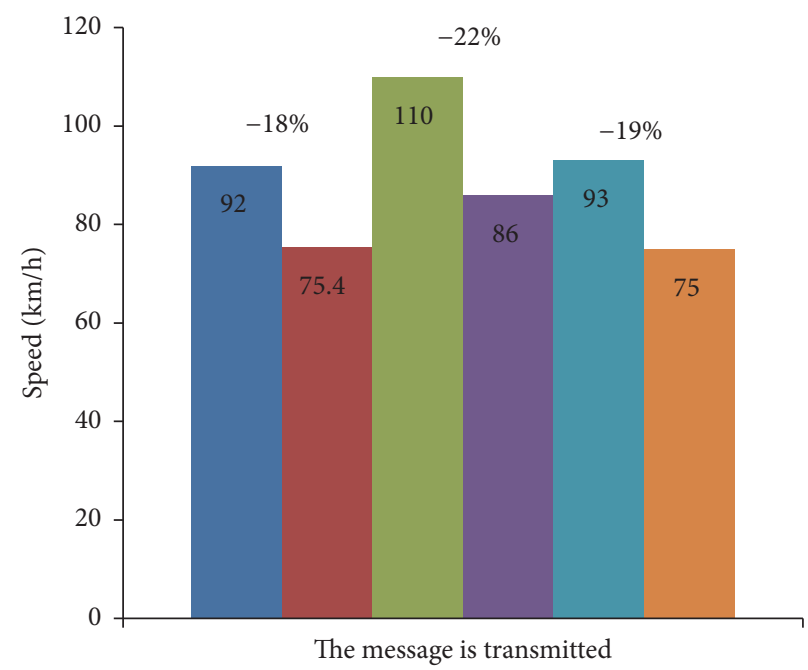

- Mean speed before sending the message (upstream area)

- Mean speed after sending the message (downstream area)

- 85th percentile speed before sending the message (upstream area)

- 85th percentile speed after sending the message (downstream area)

n 50th percentile speed before sending the message (upstream area)

- 50th percentile speed after sending the message (downstream area)

Figure 10: The effect of the Voice Sign System on mean, 50th percentile, and 85 th percentile speed of vehicles.

A summary of the changes in vehicles' mean speed in the status of sending the message is illustrated in Table 3 and indicates that sending the message resulted in $18 \%$ reduction in speed $(\mathrm{SD}=15.8)$.

4.4. Evaluation of the Effectiveness of VSS on the Speed Limit Observation. According the results at this study the effectiveness of VSS was apparent and led to speed reduction. As to improve the accuracy of evaluations, improvement in 
TABLE 4: The recorded speed when a message is transmitted.

\begin{tabular}{|c|c|c|c|c|}
\hline Status & $\begin{array}{c}\text { Before message transmission } \\
\text { (upstream area) }\end{array}$ & $\begin{array}{c}\text { After message transmission } \\
\text { (downstream area) }\end{array}$ & Frequency & $\begin{array}{l}\text { Frequency } \\
\text { percentage }\end{array}$ \\
\hline Status 1 & Exceeding the speed limit & Observing the speed limit & 236 vehicles & 46.5 \\
\hline Status 2 & Exceeding the speed limit & Exceeding the speed limit & 147 vehicles & 28.9 \\
\hline Status 3 & Observing the speed limit & Exceeding the speed limit & 16 vehicles & 3.1 \\
\hline Status 4 & Observing the speed limit & Observing the speed limit & 109 vehicles & 21.5 \\
\hline
\end{tabular}

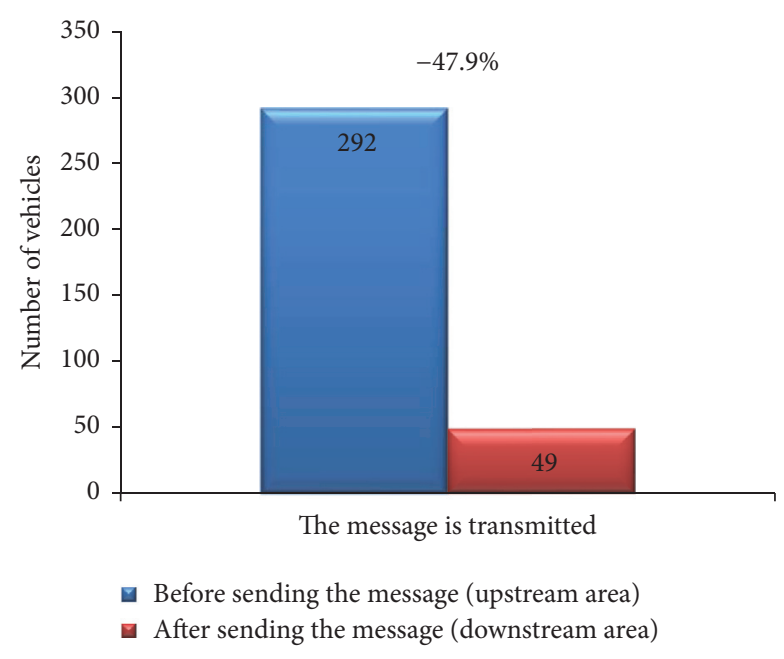

FIGURE 11: The effect of the VSS on exceeding the speed limit by $10 \mathrm{~km} / \mathrm{h}$ or more.

sending the message was studied to observe the speed limit of $80 \mathrm{~km} / \mathrm{h}$. Table 4 demonstrates the summary of the frequency results for the status of observing and not observing the speed limit, before and after message transmission.

Status 1 confirms the effectiveness of the Voice Sign System on observing the speed limit. It proves to be successful as the drivers reduced the speed to the speed limit after hearing the message. Therefore, it can be concluded that the Voice Sign System is accountable for $46.5 \%$ of following the speed limit and reducing the speed.

A number of drivers were directly influenced, so that they responded to the voice message and reduced their speed. However, some others had to reduce their speed as a result of the speed reduction of the vehicle ahead. In other words, they were indirectly influenced by the voice message. Also, according to the conducted survey $18.2 \%$ of drivers were listening to the four radio frequencies in which the message was being transmitted. Assuming all drivers who heard the message reduced their speed, then $18.2 \%$ were directly affected by the message and $28.3 \%$ were indirectly affected and reduced their speed to the speed limit or lower than that.

Moreover, with reference to Figures 11 and 12, after hearing the message, the possibility of exceeding the speed limit by $10 \mathrm{~km} / \mathrm{h}$ or more is reduced by $47.9 \%$ (18.2\% are directly influenced and $29.7 \%$ are indirectly influenced). Also, the possibility of exceeding the speed limit by $20 \mathrm{~km} / \mathrm{h}$ or more is reduced by $31 \%$ (18.2\% are directly influenced and $12.8 \%$ are indirectly influenced).

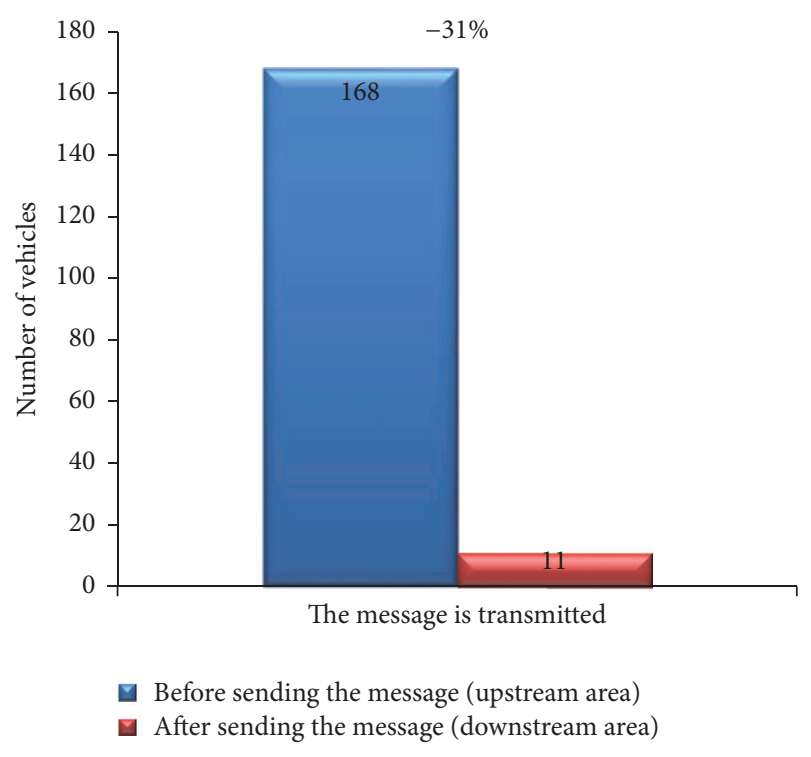

FIGURE 12: The effect of the VSS on exceeding the speed limit by $20 \mathrm{~km} / \mathrm{h}$ or more.

TABLE 5: Skewness and Kurtosis of speed data.

\begin{tabular}{lcc}
\hline Subject & Skewness & Kurtosis \\
\hline $\begin{array}{l}\text { Speed in the upstream area (the message is } \\
\text { transmitted) }\end{array}$ & -0.178 & -0.302 \\
$\begin{array}{l}\text { Speed in the downstream area (the message is } \\
\text { transmitted) }\end{array}$ & 0.056 & 0.349 \\
$\begin{array}{l}\text { Difference between the speed in the upstream } \\
\text { and downstream (the message is transmitted) }\end{array}$ & 0.206 & -0.180 \\
$\begin{array}{l}\text { Speed in the upstream area (no message is } \\
\text { transmitted) }\end{array}$ & -0.062 & -0.264 \\
$\begin{array}{l}\text { Speed in the downstream area (no message is } \\
\text { transmitted) }\end{array}$ & 0.230 & 0.549 \\
$\begin{array}{l}\text { Difference between the speed in the upstream } \\
\text { and downstream (no message is transmitted) }\end{array}$ & 0.077 & -0.382 \\
\hline
\end{tabular}

4.5. Data Validation. Statistical tests were performed to validate the collected data. In order to determine the normality of the data, Skewness and Kurtosis of speed data were used. Table 5 shows the normality of the data frequency as a value falls in the range of $(-2,2)$.

In order to ensure the normality of speed data frequency, the Shapiro-Wilk and Kolmogorov-Smironov tests were utilized. As Table 6 illustrates, the amount of $P$ value is more than 0.05 ; thus, data frequencies are normal. In addition, in 
TABLE 6: Test results of analyzing data normalization.

\begin{tabular}{lcc}
\hline Subject & Shapiro-Wilk & Kolmogorov-Smironov \\
\hline Speed in the upstream area (the message is transmitted) & $P=0.431$ & $P=0.200$ \\
Speed in the downstream area (the message is transmitted) & $P=0.538$ & $P=0.200$ \\
Difference between the speed in the upstream and downstream (the message is transmitted) & $P=0.485$ & $P=0.078$ \\
Speed in the upstream area (no message is transmitted) & $P=0.066$ & $P=0.184$ \\
Speed in the downstream area (no message is transmitted) & $P=0.290$ & $P=0.200$ \\
Difference between the speed in the upstream and downstream (no message is transmitted) & $P=0.049$ & $P=0.200$ \\
\hline
\end{tabular}

TABLE 7: Result of Student's $t$-test for comparing the speed in the upstream and downstream while transmitting a message and no message transmission.

\begin{tabular}{lcc}
\hline Subject & Type of $t$-test & $t$ \\
\hline $\begin{array}{l}\text { Vehicle speed in the upstream (the message is transmitted) } \\
\text { Vehicle speed in the downstream (the message is transmitted) }\end{array}$ & Paired-samples $t$-test & 23.7 \\
$\begin{array}{l}\text { Vehicle speed in the upstream (no message is transmitted) } \\
\text { Vehicle speed in the downstream (no message is transmitted) }\end{array}$ & Paired-samples $t$-test & -0.352 \\
$\begin{array}{l}\text { Speed changes while transmitting the message } \\
\text { Speed changes while no message is transmitted }\end{array}$ & Independent-samples $t$-test & -15.8 \\
\hline
\end{tabular}

order to study the significance of the results, $t$-test should be applied.

A $t$-test was conducted to study the significance of the difference between mean speeds. The results are indicated in Table 7 with $5 \%$ error rate. Results show that the difference between the mean speed in the upstream $(M=92 ; \mathrm{SD}=$ 16.5) and downstream $(M=75.4 ; \mathrm{SD}=11.4)$ traffic while transmitting the message is statistically significant indicating the effect of the message on reducing the speed $(t(507)=23.7$; $P<0.001)$. However, when no messages are transmitted, the difference between the mean speed in the upstream $(M$ $=68.5 ; \mathrm{SD}=7.9)$ and downstream $(M=68.8 ; \mathrm{SD}=9.1)$ of the area is nonsignificant, and the speed remains almost steady $(t(157)=-0.352 ; P=0.725)$. Also, the test was studied independently for speed changes while transmitting the message $(M=-16.6 ; \mathrm{SD}=15.8)$ and no message transmission $(M=0.28 ; \mathrm{SD}=10.2)$. The hypothesis is rejected due to the obtained results which are less than 0.05 , and it proves the dissimilarity between the speed changes in two statuses $(t(410)=-15.8 ; P<0.001)$.

\section{Conclusion}

In this research the effect of the Voice Message System (VSS) on speed reduction in Yadegar-e-Imam expressway located in Tehran is analyzed. The results of the collected data areas are listed in the following.

(1) When the message is transmitted at upstream area, $24.6 \%$ of vehicles are travelling at $80 \mathrm{~km} / \mathrm{h}$ or slower that reach to $67.9 \%$ in downstream area owing to message transmission.

(2) Mean speed, 50th percentile speed, and 85th percentile speed of the vehicles are reduced to $18 \%, 19 \%$, and $22 \%$, respectively, by message transmission. In terms of speed, the percentages are equal to speed reduction of $16.61,18$, and $24 \mathrm{~km} / \mathrm{h}$, respectively.

(3) The VSS on average yields to $18 \%$ speed reduction in the area under study.

(4) Generally, $46.5 \%$ of the drivers are influenced directly by VSS leading to reducing their speed to the assigned speed limit out of which $18.2 \%$ are directly and $28.3 \%$ are indirectly influenced by the message.

(5) Prior to message transmission, $57.5 \%$ of drivers drive at the speed of $90 \mathrm{~km} / \mathrm{h}$ or faster which is reduced to $9.6 \%$ after sending the message. Therefore, the possibility of drivers who drive $10 \mathrm{~km} / \mathrm{h}$ faster than the speed limit reduced by $47.9 \%$ in which $18.2 \%$ is the direct and $27.9 \%$ is the indirect result of the message.

(6) When the voice message was sent, 33\% of drivers were travelling at the speed of $100 \mathrm{~km} / \mathrm{h}$ or faster. However, by hearing the message, only $2 \%$ of the drivers travelled faster than $100 \mathrm{~km} / \mathrm{h}$. Therefore, the possibility of driving $20 \mathrm{~km} / \mathrm{h}$ faster than the speed limit was reduced by $31 \%$ in which $18.2 \%$ is the direct and $12.8 \%$ is the indirect result of the message.

In special conditions such as night time or adverse weather conditions in which the visibility is poor, the Voice Sign System assists drivers in getting the information by their hearing sense and response accordingly (messages such as declaring the appropriate speed). Additionally, voice messages can reduce elderly drivers' errors that steam from prolonged reaction time to visual messages and poor eye sight. Also, the system helps the inexperienced drivers who do not pay enough attention to the signs and tend to be more aggressive. In other words, the system acts as a complementary method along with other traffic calming and controlling measures to improve road safety. 


\section{Competing Interests}

The authors declare that they have no competing interests.

\section{References}

[1] WHO, Global Status Report on Road Safety, World Health Organization, Geneva, Switzerland, 2013.

[2] Iranian Legal Medicine Organization, 2013, http://www.lmo.ir.

[3] “Tehran Traffic Control Company," 2013, http://trafficcontrol .tehran.ir/.

[4] M. Aadresi, A. Zahedi, M. G. Zarrinkia, and H. Beheshti, "Communication speed and speed limits data on the safety net," Iranian Rahvar Police Journal. Rahvar Iranian Traffic Police, pp. 65-78, 2010.

[5] American Association of State Highway (AASHTO) and Transportation Officials, Highway Safety Manual (HSM), vol. 1, AASHTO, Washington, DC, USA, 2010.

[6] DOWL Engineers, Traffic Calming Protocol Manual (TCPM), DOWL Engineers, Anchorage, Alaska, USA, 2001.

[7] S. C. Davis, U. Dot, S. C. Tignor et al., "Innovative Traffic Control Technology and Practice in Europe," 1999.

[8] Washington State Department of Transportation (WSDOT), INTELLIGENT TRANSPORTATION SYSTEM ( ITS ) Design Guide, vol. 9710, 2004.

[9] B. Antić, D. Pešić, M. Vujanić, and K. Lipovac, “The influence of speed bumps heights to the decrease of the vehicle speedbelgrade experience," Safety Science, vol. 57, pp. 303-312, 2013.

[10] L. J. Mountain, W. M. Hirst, and M. J. Maher, "Are speed enforcement cameras more effective than other speed management measures? The impact of speed management schemes on 30 mph roads," Accident Analysis and Prevention, vol. 37, no. 4, pp. 742-754, 2005.

[11] H. Ding, X. Zhao, J. Rong, and J. Ma, "Experimental research on the effectiveness of speed reduction markings based on driving simulation: a case study," Accident Analysis and Prevention, vol. 60, pp. 211-218, 2013.

[12] A. Drakopoulos and G. Vergou, "Evaluation of the converging chevron pavement marking pattern at one wisconsin location," 2003.

[13] M. H. Cameron, A. Cavallo, and A. Gilbert, Crash-Based Evaluation of the Speed Camera Program in Victoria 1900-1991; Phase 1: General Effects; Phase 2: Effects of Program Mechanisms, no. 42, 1992.

[14] R. A. Retting, S. Y. Kyrychenko, and A. T. McCartt, "Evaluation of automated speed enforcement on Loop 101 freeway in Scottsdale, Arizona," Accident Analysis and Prevention, vol. 40, no. 4, pp. 1506-1512, 2008.

[15] X. Zhang, P. Liu, F. Huang, and H. Yu, "Evaluation of the speed reduction effects of automated speed enforcements on freeways," in Proceedings of the 11th International Conference of Chinese Transportation Professionals: Towards Sustainable Transportation Systems (ICCTP '11), pp. 2061-2071, August 2011.

[16] World Road Association (PIARC), "Road safety Manual (RSM)," 2003.

[17] I. Pool, "RDS, Radio Data System," Resources and analysis for electronics engineers, 2013, http://www.radio-electronics .com/info/broadcast/rds/radio-data-system-basics-tutorial.php.

[18] “History of VICS," VICS Web Site, 2013, http://www.vics.or.jp/ english/about/history.html.
[19] "National Highway Traffic Safety Administration (NHTSA)," 2012, http://www.nhtsa.gov/.

[20] Ponabaadi, Seasonal Survey on the Programms Broadcasted by IRIB Summer 2011, IRIB Research Center, Department of Social Research and Programm Evaluation, 2011.

[21] Najafiasl, Seasonal Survey on the Programms Broadcasted by IRIB Summer 2012, IRIB Research Center, Department of Social Research and Programm Evaluation, Tehran, Iran, 2012.

[22] Madani and Pirhayati, Seasonal Survey on the Programms Broadcasted by IRIB Spring 2012, Seasonal Survey on the Programms Broadcasted by IRIB Spring 2012, Tehran, Iran, 2012. 


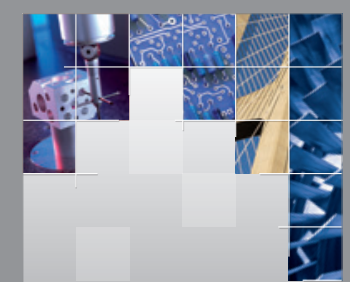

\section{Enfincering}
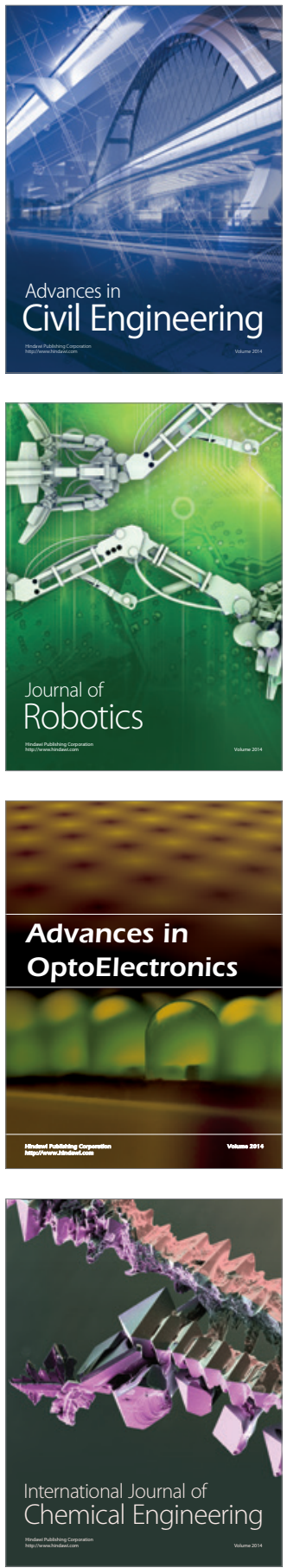

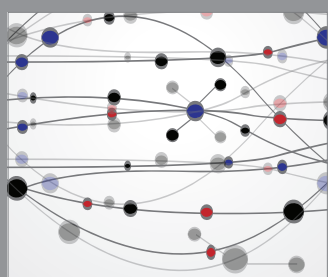

The Scientific World Journal

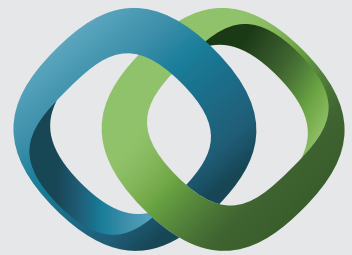

\section{Hindawi}

Submit your manuscripts at

https://www.hindawi.com
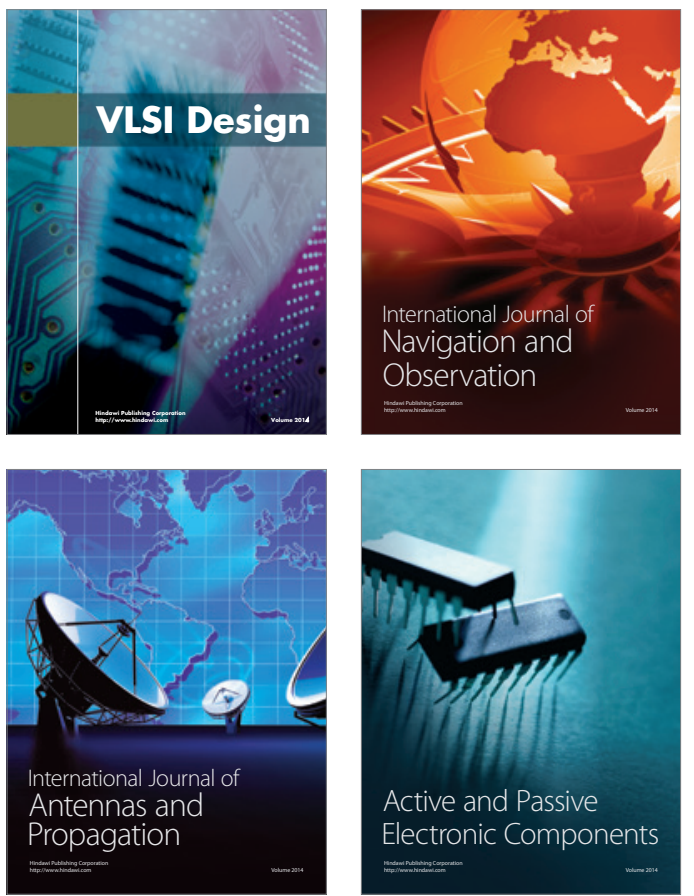
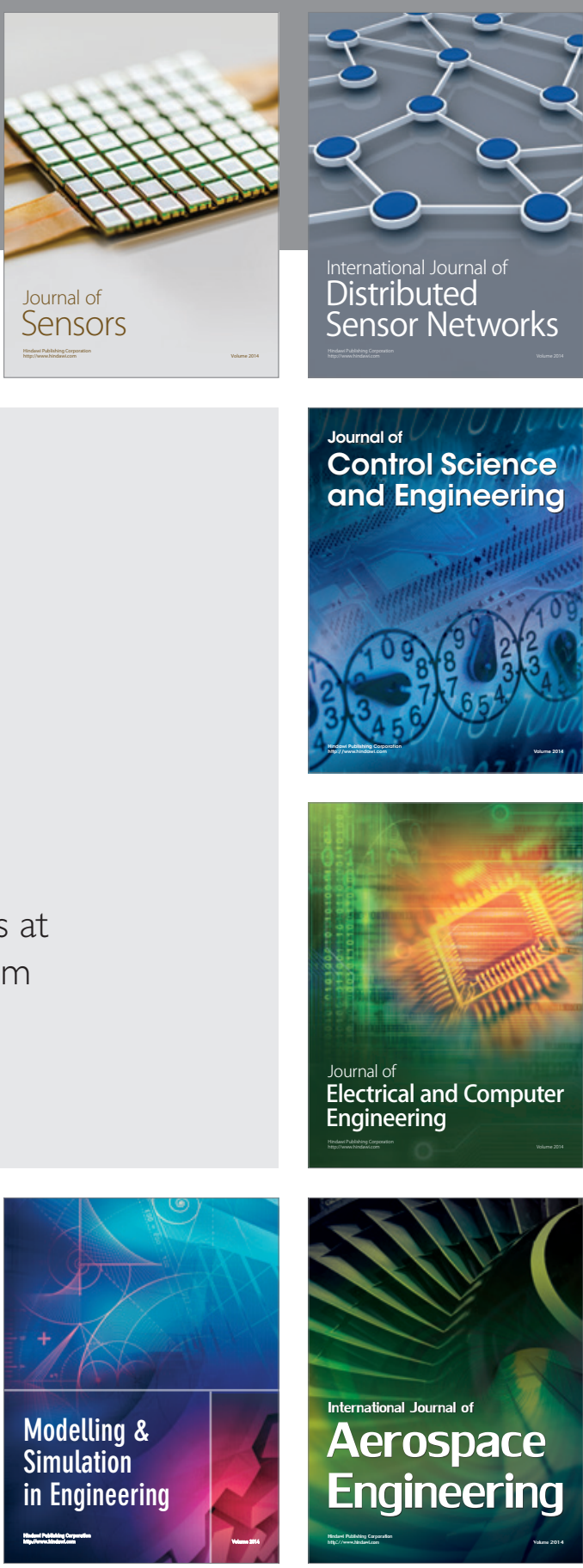

International Journal of

Distributed

Sensor Networks

$-$

Joumal of

Control Science

and Engineering
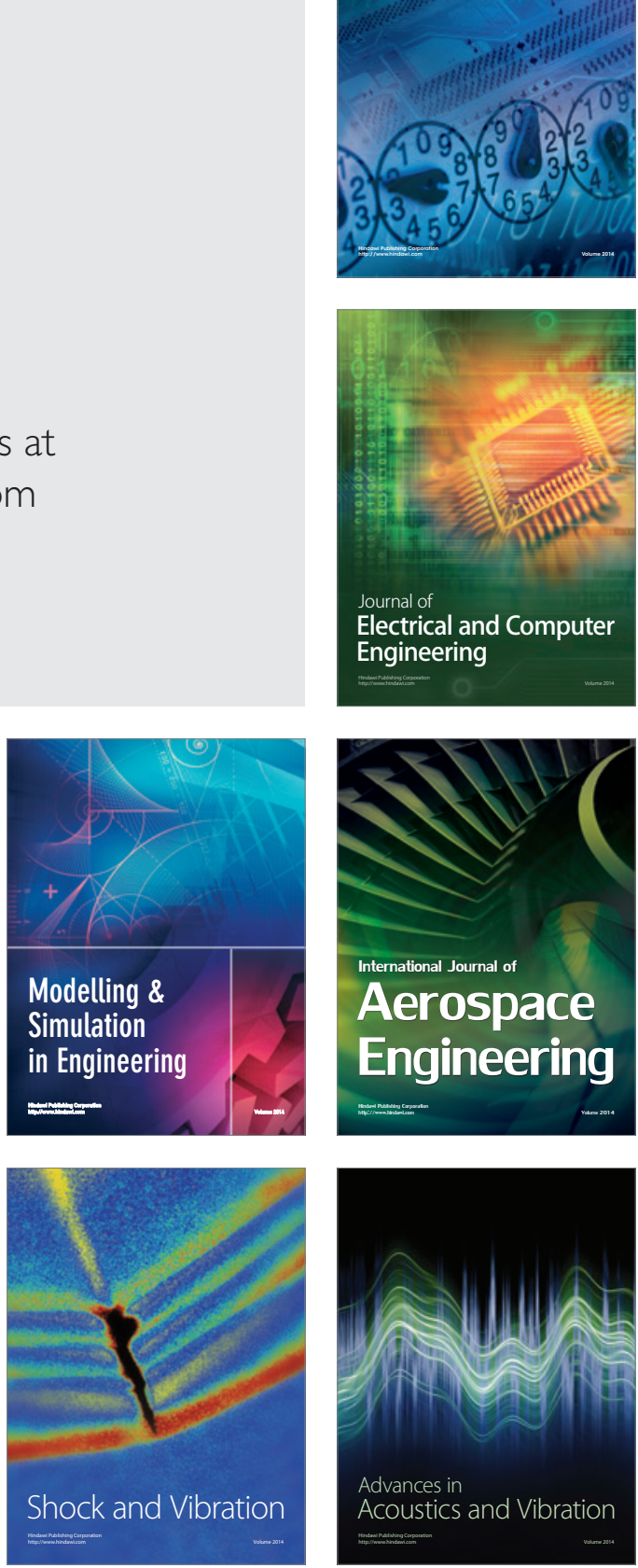